\title{
Comparative Study between the Synchronous Motor to Permanent Magnets and Axial Flux (MSAP) and its Equivalent to Coiled Rotor (MSRB)
}

\author{
Souhir Tounsi \\ National School of Electronics and Telecommunications of Sfax, SETIT-Research Unit, Sfax University, Sfax, Tunisia \\ Email address: \\ souhir.tounsi@enetcom.rnu.tn
}

\section{To cite this article:}

Souhir Tounsi. Comparative Study between the Synchronous Motor to Permanent Magnets and Axial Flux (MSAP) and its Equivalent to Coiled Rotor (MSRB). International Journal of Electrical Components and Energy Conversion. Vol. 1, No. 3, 2015, pp. 69-74.

doi: 10.11648/j.ijecec.20150103.11

\begin{abstract}
This work consists in conceiving of a coiled rotor synchronous motor equivalent to a permanent magnet axial-flux motor for electric vehicle by the joint method analytical / finite elements. An analytical model sizing motor is developed by the finite element method. A comparison between a 4 pairs of poles 6 teeth structure of a permanent magnet axial-flux motor and the studied motor is made in the goal to select the most effective structure for the same strength and same electric constant.
\end{abstract}

Keywords: Design, Electric Motor, Finite Element, Selection, Modularity

\section{Introduction}

This paper present a design methodology of a synchronous motor structure to coiled rotor (MSRB) equivalent to the motor with permanent magnets and axial flux (MSAP) studied in [1], [2] and [3], by the finite element method using the software MAXWELL 2D.

The gait followed during the design of this motor is similar to the one established for the MSAP [1], [2] and [3]. Indeed the whole basis calculation makes itself for the MSAP then we study help in the software MAXWELL 2D the rotor parameters already conceived while replacing every magnet by a coil permitting to come closer to the maximum of the results gotten for the MSAP in order to assure the equivalence of two structure.

\section{Geometric Parameters of the Motor}

\subsection{Motor Structure}

The geometric parameters of the MSRB are already calculated from those calculated for the MSAP [1], [2] and [3].

The MSAP machine is built with the same radius for the stator and the rotor. The slots directed towards the motor's center. The magnets shape is the same than the main teeth. Three design ratios define the motor's structure.

The first coefficient is the ratio $\beta$ of the magnet average angular width by the pole pitch $(\mathrm{L}=\pi / \mathrm{p})$. It adjusts the magnet width in versus the poles number chosen.
The second coefficient $(\alpha)$ is the ratio of the main tooth average angular width by the average angular width of a magnet. It adjusts the main tooth size and has a strong influence on the electromotive force waveform. Here, it is fixed at one.

The last coefficient fixes the inserted tooth size. It's the ratio of the main tooth average width by an inserted tooth average width.

The advantage of these coefficients is to define quickly machine shape. However, they are based on the average radius and it is necessary to compute and check higher and lower angles teeth in order to avoid any intersection.

The MSAP and MSRB equivalents structures are illustrated by figure 1 :

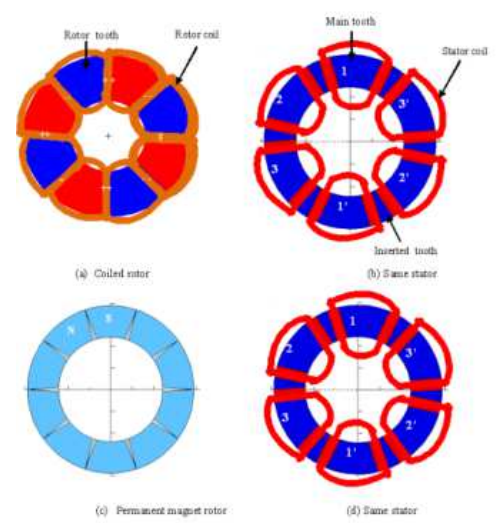

Figure 1. MSAP and MSRB equivalents structures. 


\subsection{Geometric Parameters of the Stator}

The geometric parameters of the MSRB stator remain unaltered since we kept the one of the MSAP.

The figure 2 presents the different geometric parameters of the stator:
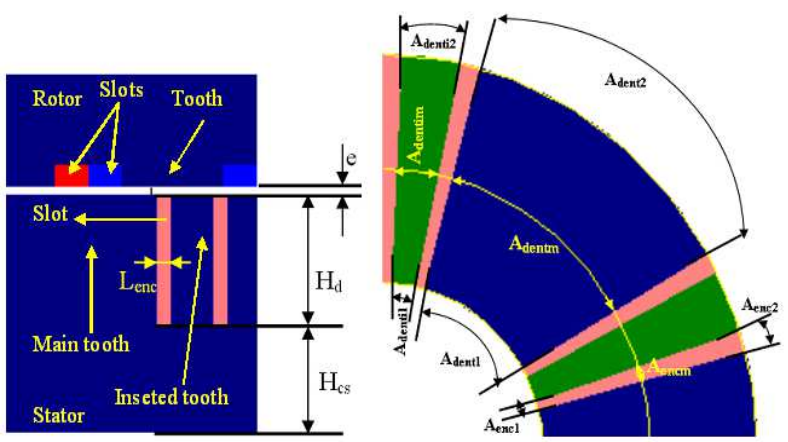

Figure 2. Geometric parameters of the MSRB stator.

\subsection{Geometric Parameters of the Rotor}

The rotor of the MSRB is gotten while replacing every magnet by a very determined winding so that it is equivalent to the rotor of the MSAP (figure 3).
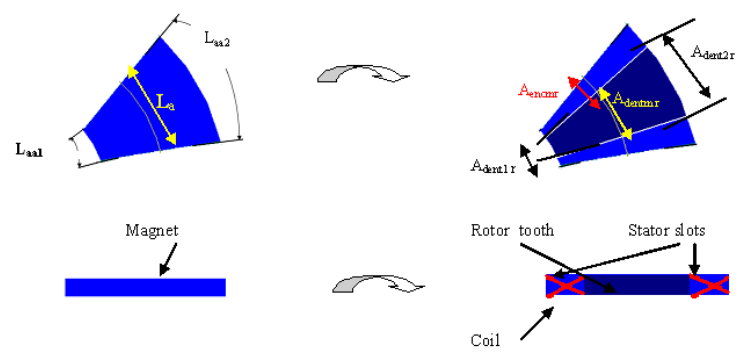

Figure 3. Replacement of the magnets of the MSAP by a winding for the MSRB.

This equivalence is assured by:

- Conservation of the rotor yoke thickness calculated for the MSAP. So Hcr doesn't change.

- The middle width of a rotor slot is as:

$$
\mathrm{A}_{\text {encmr }}=\gamma \mathrm{L}_{\mathrm{a}}
$$

With $\mathrm{La}$ is the middle width of the magnet and $\gamma$ is a coefficient adjusted by finite element simulations with the help of the software Maxwell 2D and can be optimized.

- The height of a rotor tooth Hdr permitting to reserve the necessary space for the copper:

$$
\mathrm{H}_{\mathrm{dr}}=\frac{\mathrm{n}_{\mathrm{s}} \mathrm{I}_{\mathrm{e}}}{\delta \mathrm{L}_{\mathrm{encr}}}
$$

Where ns is the number of spire of the rotor coil, Ie is the current of excitation and $\delta$ is the admissible current density in the copper.

The figure 4 presents the different geometric parameters of the rotor.

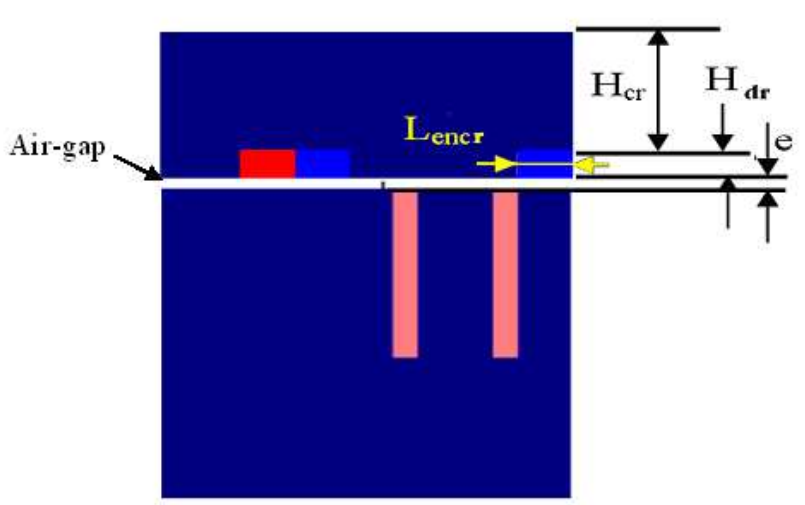

Figure 4. Different geometric parameters of the rotor.

\section{Analytical Computation}

\subsection{Modularity}

For applications to elevated current, we collects several floors on the motor axis to reduce the rotor flux and thereafter we remedy to the distortion of the stator flux and consequently back electromotive force.

\subsection{Flux and Back Electromotive Force}

By analogy with the analytic calculation made for the MSAP [1-3], back electromotive force captured by the winding comes from the derivative of the flux, it's necessary to be therefore capable to express the flux according to the position of the magnets. As the shows in the figure 5, the magnetic induction is supposed perfectly rectangular to the level of the air-gap. The leakages between the air-gap and the stator are disregarded. With these hypotheses, the flux captured by a coil can expressed as follow:

$$
\phi_{\mathrm{b}}=\int_{\text {Tooth section }} \mathrm{B}_{\mathrm{e}}(\theta) \mathrm{ds}
$$

The figure 5- (b) represents the distribution of the vector induction to the level of the air-gap for the functioning at no load of the two types of motor. The level of induction is identical for the two cases and reaches the value calculated analytically. For the MSRB, the excitation current is equal to 7A driving to the equivalence of the MSRB and MSAP.

From an initial position illustrated by figure 5-(a), rotor moves with angular velocity $(\Omega=d \theta / d t)$. Four distinct intervals appear according to magnets positions and geometrical parameters values defined previously. Table 1 illustrates these different intervals as well as flux variation for each position. In the zone ' $a$ ' the flux is constant because magnet and tooth length are different. If $\alpha$ is equal to 1 , zone ' $a$ ' disappears. In the zone ' $b$ ', the flux decreases because a part of the magnet is not in front of the tooth. In the zone ' $c$ ', a magnet of an opposite polarity overlaps also the main tooth. Consequently, the flux varies 2 times more quickly. Finally, the zone' $d$ ' is identical to the zone ' $b$ '. These two zones exist only if the coefficient $\beta$ is less than 1 . 


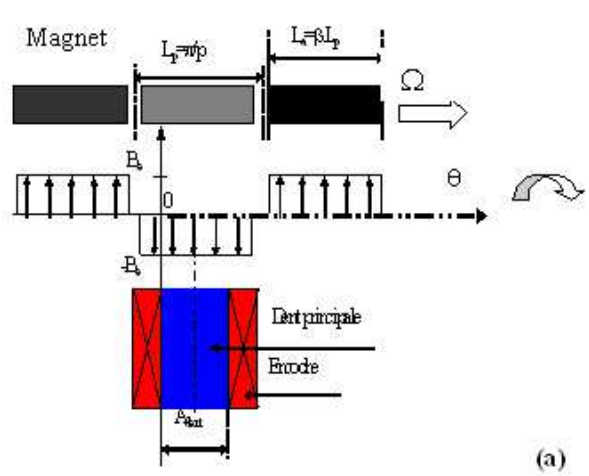

Rotor Slots Rotor tooth Coils

(a)
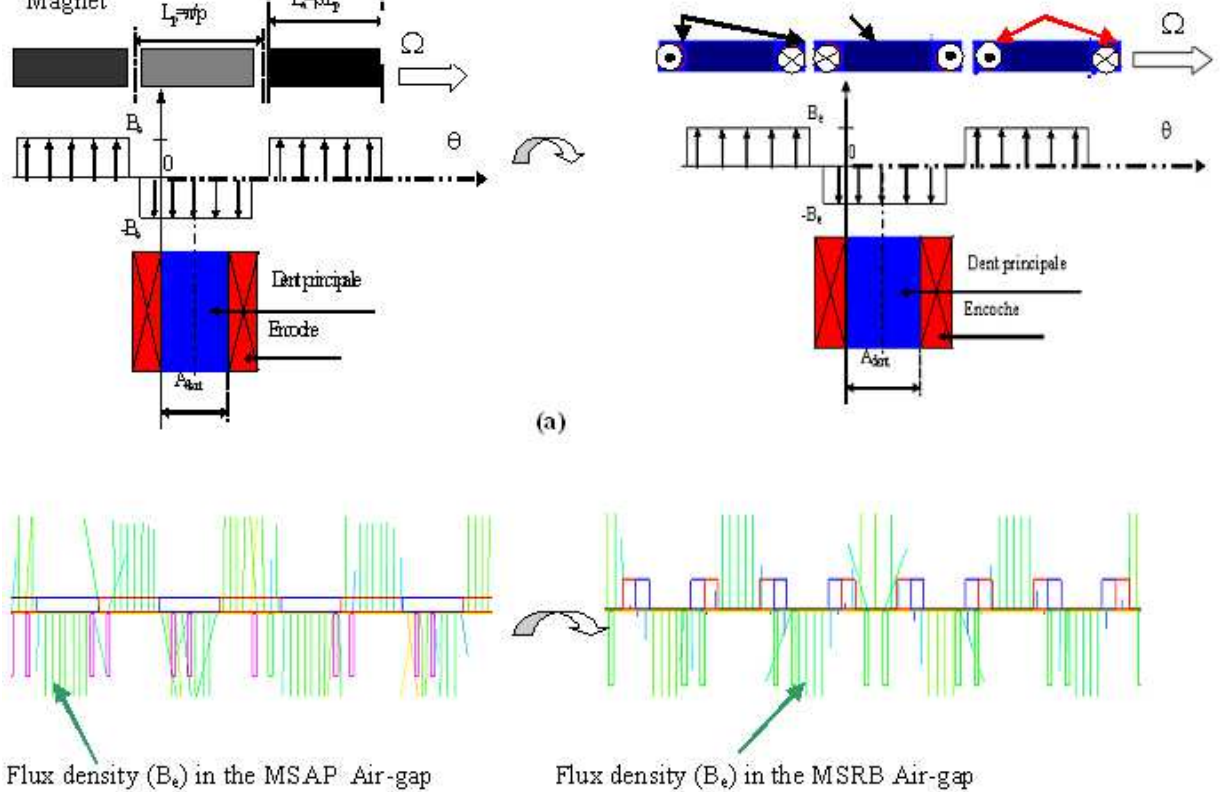

Flux density $\left(B_{e}\right)$ in the MSRB Air-gap

(b)

Figure 5. Initial position and induction in the air-gap.

The global phase back electromotive force is well proportional to the angular speed, to the number of spires by phase Nsph and to the derivative of the flux in relation to the mechanical angle. It's given by the following equation [4-12]:

$$
\mathrm{E}=-\mathrm{N}_{\mathrm{sph}} \frac{\mathrm{d} \phi_{\mathrm{b}}}{\mathrm{d} \theta} \Omega
$$

The figure 6 presents the evolution of the flux and the electromotive force (f.c.e.m.) on one electric period. We note that strongest variation of flux happens in the zone ' $c$ '. In practice the zones ' $b$ ' and 'd'are generally weak and are smoothed by the flux leakages.

have a trapezoidal shape or sinusoidal of the f.c.e.m., is it necessary to fix the appropriated values of $\beta$ and $\alpha$. For example, for a BDC machine (Brushless DC motor), it is necessary that $\beta$ and $\alpha$ are near of the unit in order to have the width of the landing of the f.c.e.m. largest possible [4-12].

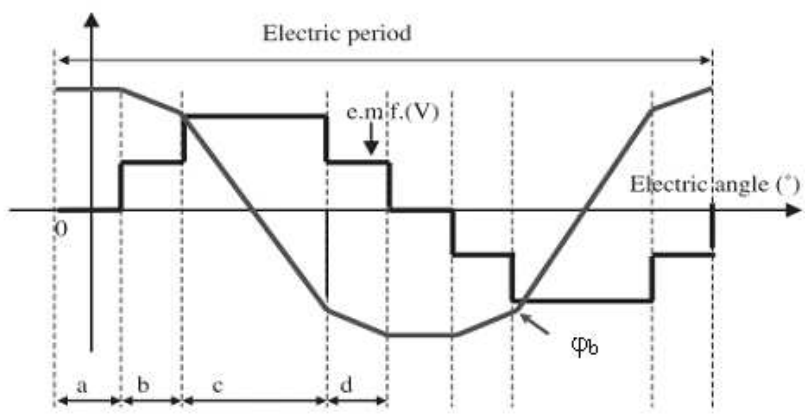

Figure 6. Flux and electromotive force in function of electric angle.

Table 1. Flux and electromotive force in function of motor parameters.

\begin{tabular}{llll}
\hline Zone & Position (rad) & Flux $\varphi_{\mathrm{b}}(\mathbf{W b})$ & Emf (V) \\
\hline $\mathrm{a}$ & $-\frac{\pi \beta}{2 \mathrm{p}}(1-\alpha) \leq \theta \leq \frac{\pi \beta}{2 \mathrm{p}}(1-\alpha)$ & $\frac{\left(\mathrm{D}_{\mathrm{ext}}^{2}-\mathrm{D}_{\mathrm{int}}^{2}\right)}{8} \beta \frac{\pi}{\mathrm{p}} \alpha \mathrm{B}_{\mathrm{e}}$ & 0 \\
$\mathrm{~b}$ & $\frac{\pi \beta}{2 \mathrm{p}}(1-\alpha) \leq \theta \leq \frac{\pi}{\mathrm{p}}\left[1-\frac{\beta}{2}(1+\alpha)\right]$ & $\frac{\left(\mathrm{D}_{\mathrm{ext}}^{2}-\mathrm{D}_{\mathrm{int}}^{2}\right)}{8}\left(\frac{\pi \beta}{2 \mathrm{p}}(1+\alpha)-\theta\right) \mathrm{B}_{\mathrm{e}}$ & $\mathrm{N}_{\mathrm{sph}} \Omega_{\mathrm{m}} \frac{\left(\mathrm{D}_{\mathrm{ext}}^{2}-\mathrm{D}_{\mathrm{int}}^{2}\right)}{8} \mathrm{~B}_{\mathrm{e}}$ \\
$\mathrm{c}$ & $\frac{\pi}{\mathrm{p}}\left[1-\frac{\beta}{2}(1+\alpha)\right] \leq \theta \leq \frac{\pi \beta}{2 \mathrm{p}}(1+\alpha)$ & $\frac{\left(\mathrm{D}_{\mathrm{ext}}^{2}-\mathrm{D}_{\mathrm{int}}^{2}\right)}{8}\left(\frac{\pi}{\mathrm{p}}-2 \theta\right) \mathrm{B}_{\mathrm{e}}$ & $2 \mathrm{~N}_{\mathrm{sph}} \Omega_{\mathrm{m}} \frac{\left(\mathrm{D}_{\mathrm{ext}}^{2}-\mathrm{D}_{\text {int }}^{2}\right)}{8} \mathrm{~B}_{\mathrm{e}}$ \\
$\mathrm{d}$ & $\frac{\pi \beta}{2 \mathrm{p}}(1+\alpha) \leq \theta \leq \frac{\pi}{\mathrm{p}}\left[1-\frac{\beta}{2}(1-\alpha)\right]$ & $\frac{\left(\mathrm{D}_{\mathrm{ext}}^{2}-\mathrm{D}_{\mathrm{int}}^{2}\right)}{8}\left(\frac{\pi}{\mathrm{p}}-\left[\frac{\pi \beta}{2 \mathrm{p}}(1+\alpha)\right]-\theta\right) \mathrm{B}_{\mathrm{e}}$ & $\mathrm{N}_{\mathrm{sph}} \Omega_{\mathrm{m}} \frac{\left(\mathrm{D}_{\mathrm{ext}}^{2}-\mathrm{D}_{\mathrm{int}}^{2}\right)}{8} \mathrm{~B}_{\mathrm{e}}$ \\
\hline
\end{tabular}




$$
\mathrm{B}_{\mathrm{e}}=\frac{\mu_{0} \mathrm{nI}_{\mathrm{e}}}{\mathrm{e}}
$$

\subsection{Electromagnetic Torque}

The instantaneous electromagnetic power developed by the motor $\mathrm{Pe}(\mathrm{t})$ is expressed by the following equation:

$$
P_{e}(t)=\sum_{i=1}^{m} e_{i}(t) i_{i}(t)
$$

Where ei $(\mathrm{t})$ and $i(\mathrm{t})$ are respectively back the electromotive force and the current of the i phase according to the time.

For a powering with rectangular currents in phase with the electromotive force, the instantaneous power is equal to its middle value Pe:

$$
\mathrm{Pe}=2 \mathrm{EI}
$$

Where E and I are respectively the maximal value of electromotive force and the maximal value of the current.

The electromagnetic torque developed by the motor is given by the following expression:

$$
\mathrm{C}_{\mathrm{e}}=2 \frac{\mathrm{EI}}{\Omega}
$$

The landing of the f.c.e.m. deducts from the analytic model is given by the following relation:

$$
\mathrm{E}=2 \mathrm{~N}_{\mathrm{sph}} \Omega \frac{\left(\mathrm{D}_{\mathrm{e}}^{2}-\mathrm{D}_{\mathrm{i}}^{2}\right)}{8 \mathrm{e}} \mu_{0} \mathrm{nI}_{\mathrm{e}}
$$

Where Nsph is the number of spires by phase, De and Di are respectively the external and internal diameter of the motor and Ie is the current of excitation.

From the 9 equations and 10, we deduct the expression of the torque:

$$
\mathrm{C}_{\mathrm{e}}=\mathrm{N}_{\mathrm{sph}} \frac{\left(\mathrm{D}_{\mathrm{e}}^{2}-\mathrm{D}_{\mathrm{i}}^{2}\right)}{4 \mathrm{e}} \mathrm{I} \mu_{0} \mathrm{nI}_{\mathrm{e}}
$$

While noting by $\mathrm{Ke}$ the electric constant of the motor defined by $\left(\mathrm{N}_{\mathrm{sph}} \frac{\left(\mathrm{D}_{\mathrm{e}}^{2}-\mathrm{D}_{\mathrm{i}}^{2}\right)}{2 \mathrm{e}} \mu_{0} \mathrm{nI}_{\mathrm{e}}\right)$, the expression of the torque becomes:

$$
\mathrm{Ce}=\mathrm{KeI}
$$

\section{Finite Element Modelling}

\subsection{Study in Cylindrical Cut Plan of the MSRB}

The motor is studied on a cylindrical cut plan. The plan of cut makes itself according to the middle diameter of the motor (Figure 7), When we spreads the cylindrical cut plan, we gets the model 2 D of the motor (Figure 8) [4-12].

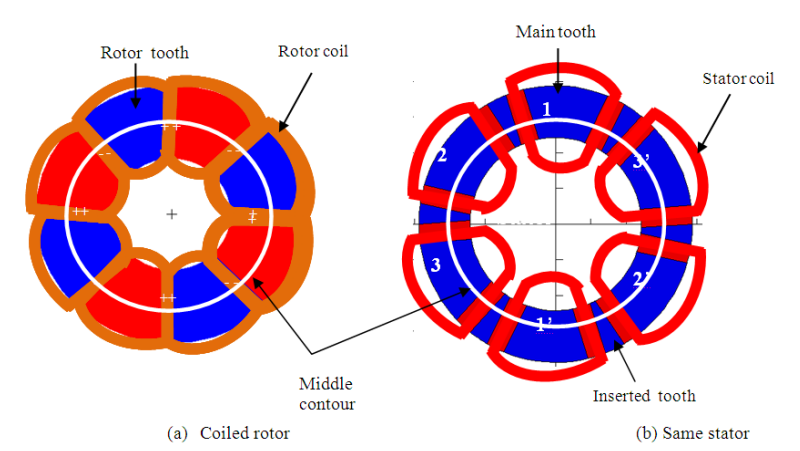

Figure 7. Schema of the motor while specifying the cut plan.

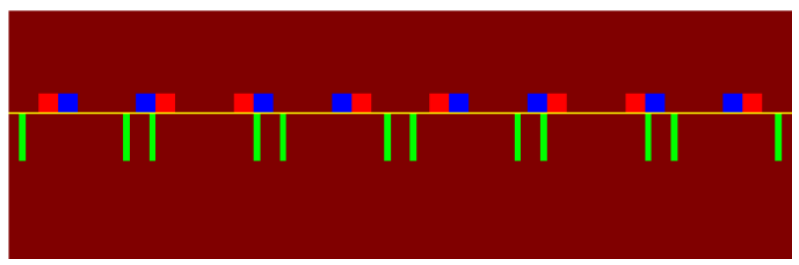

Figure 8. 2D model of the motor.

\subsubsection{Finite Element Modeling}

The finite element modeling of the MSRB requires as the MSAP a geometric representation of the motor so long as of the mesh, this last must be thinner in the air-gap because the calculation essentially takes place in this zone and in order to have a good precision of the results and a reduced time of the simulation (Figure 9) [8-12].

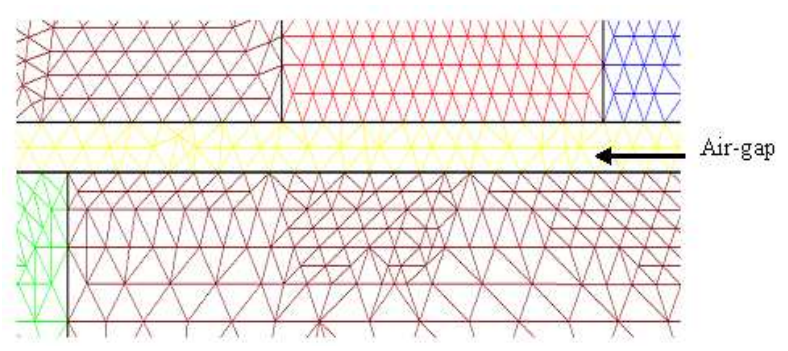

Figure 9. Geometric representation of the motor provided with the mesh.

\subsection{Comparison of the Simulation Results}

\subsubsection{Trapezoidal Case}

Figure 10 illustrates the flux at load of MSAP and MSRB.

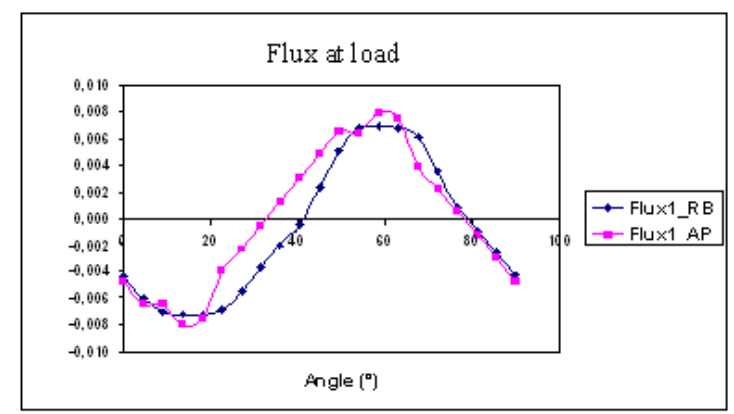

Figure 10. Flux at load of MSAP (AP) and MSRB (RB).

Figure 11 illustrates the Back electromotive force at load of MSAP and MSRB. 


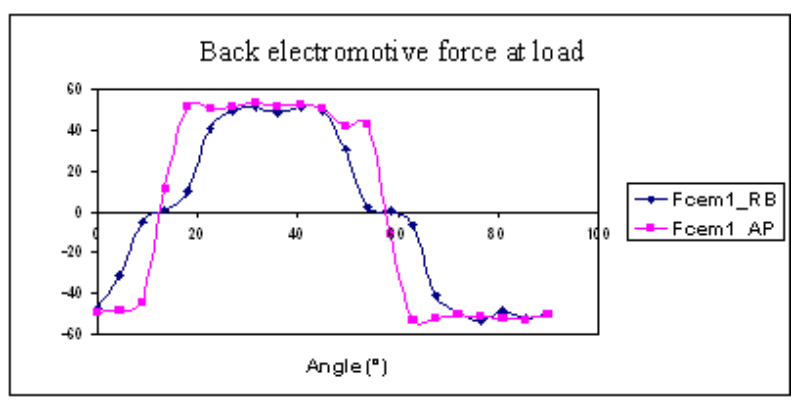

Figure 11. Back electromotive force at load of MSAP (AP) and MSRB (RB).

Figure 12 illustrates the torque at load of MSAP and MSRB.

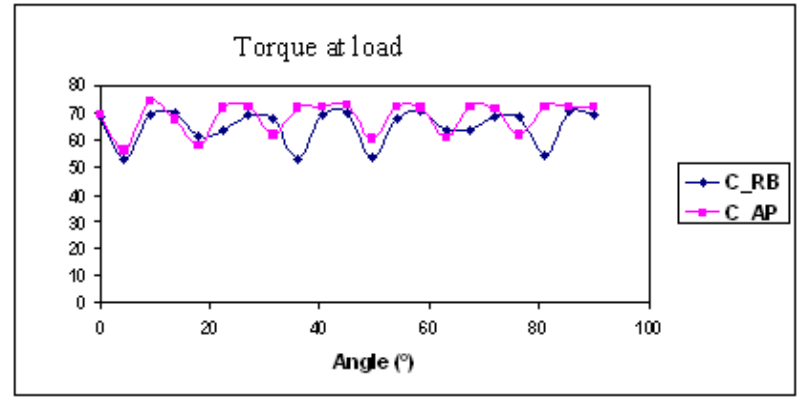

Figure 12. Torque at load of MSAP (AP) and MSRB (RB).

We notes that the curves of the flux, the back electromotive force and the torque gotten in the trapezoidal case at load for the MSRB are near of those gotten for the MSAP.

\subsubsection{Sinusoidal Case}

Figure 13 illustrates the flux at load of MSAP and MSRB.

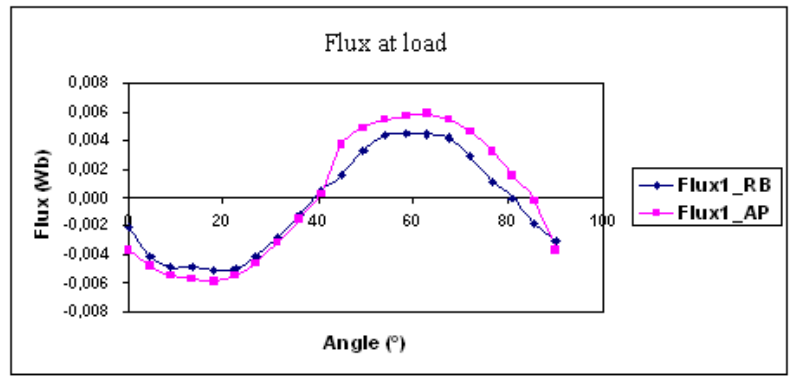

Figure 13. Flux at load of MSAP $(A P)$ and MSRB (RB).

Figure 14 illustrates the Back electromotive force at load of MSAP and MSRB.

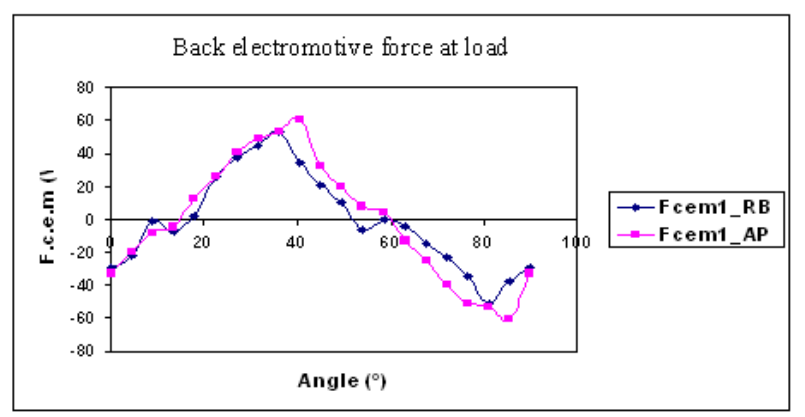

Figure 14. Back electromotive force at load of MSAP (AP) and MSRB (RB).
Figure 15 illustrates the torque at load of MSAP and MSRB.

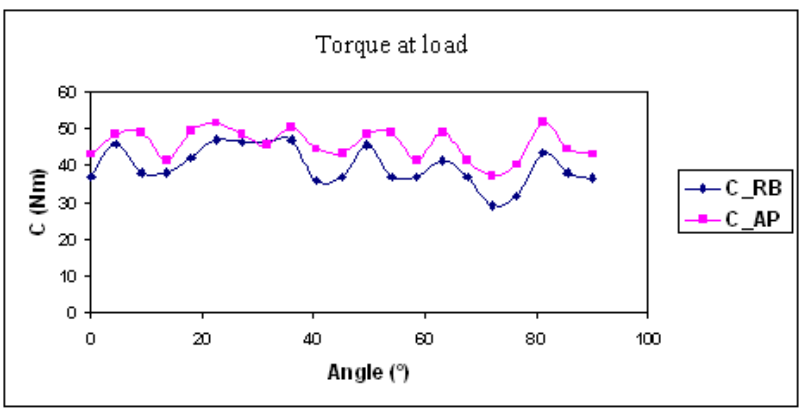

Figure 15. Torque at load of MSAP (AP) and MSRB (RB).

We note in the same that the curves of the flux, the back electromotive force and the torque gotten in the sinusoidal case at load for the MSRB are near of those gotten for the MSAP [8-12].

\section{Selection of the Most Effective Structure}

The criteria's of selection are: the efficiency, the cost and the power to weight ratio.

The following table presents the different values gotten for the MSAP and the MSRB.

Table 2. The different values gotten for the MSAP and the MSRB.

\begin{tabular}{lll}
\hline & MSAP & MSRB \\
\hline Efficiency_trap & $97,793 \%$ & $98 \%$ \\
Power to weight ratio_trap & $58,3345(\mathrm{~W} / \mathrm{Kg})$ & $55,311(\mathrm{~W} / \mathrm{Kg})$ \\
Cost_trap & $2459 \$$ & $2117 \$$ \\
Efficiency_sin & $87,970 \%$ & $92 \%$ \\
Power to weight ratio_sin & $78,541(\mathrm{~W} / \mathrm{Kg})$ & $56,077(\mathrm{~W} / \mathrm{Kg})$ \\
Cost_sin & $1518,3 \$$ & $1279 \$$ \\
\hline
\end{tabular}

According to the gotten results, we notes that the MSRB is less expensive than the MSAP, in more it presents efficiency slightly superior to the one gotten for the MSAP. On the other hand the MSRB presents a power to weight ratio lower to the one of the MSAP.

Thus, the MSRB can be the most effective structure if the user is content with its well developed power to weight ratio.

\section{Conclusion}

The comparison between the two motors allowed us to conclude that the MSRB conceived present thus a weaker cost than the one of the MSAP; We got a reduction encouraging of the price equal to $300 \$$. Besides, the MSAP has efficiency and a power to weight ratio elevated.

Thus, with these promising properties, the MSRB conceived can be an attractive solution in the world of the electric vehicles since it's especially to weak cost in relation to it's equivalence to the MSAP. 


\section{References}

[1] R. NEJI, S. TOUNSI et F. SELLAMI: "Contribution to the definition of a permanent magnet motor with reduced production cost for the electrical vehicle propulsion", European Transactions on Electrical Power (ETEP), 2006, 16: pp. 437-460.

[2] C. PERTUZA : "Contribution à la définition de moteurs à aimants permanents pour un véhicule électrique routier". Thèse de docteur de l'Institut National Polytechnique de Toulouse, Février 1996.

[3] S. TOUNSI, R. NEJI, F. SELLAMI : "Contribution à la conception d'un actionneur à aimants permanents pour véhicules électriques en vue d'optimiser l'autonomie". Revue Internationale de Génie Electrique, Volume 9/6-2006, pp. 693-718. Edition Lavoisier.

[4] Houcine MAROUANI and Souhir TOUNSI : Design of a Coiled Rotor Synchronous Motor Dedicated to Electric Traction. Journal of Electrical Systems (JES), Volume 10, Issue 3, (September 2014).

[5] Souhir TOUNSI, Ibrahim BEN SALAH and Mohamed Salim BOUHLEL: Design and control of axial flux Brushless DC motor dedicated to Electric traction. Journal of Automation \& Systems Engineering (JASE), Volume 8, Issue 2, (June 2014).

[6] Ajmia BELGACEM and Souhir TOUNSI: Optimal Control of Electric Vehicle Power Chain. Journal of Automation \& Systems Engineering (JASE), Volume 8, Issue 4, (December 2014).
[7] S. TOUNSI « Losses modelling of the electromagnetic and IGBTs converters », International Int. J. Electric and Hybrid Vehicles (IJEHV), Vol. 5, No. 1, 2013, pp:54-68.

[8] M.HADJ KACEM, S.TOUNSI et R. NEJI: « Control of an Actuator DC Energy-saving dedicated to the Electric Traction ॥; International Journal of Computer Applications (0975 - 8887) Volume 54- No.10, September 2012.pp.20-25.

[9] S. TOUNSI, M. HADJ KACEM et R. NEJI: « Design of Static Converter for Electric Traction »; International Review on Modelling and Similations (IREMOS) Volume 3, N. 6, December 2010, pp. 1189-119.

[10] Chaithongsuk, S., Nahid-Mobarakeh, B., Caron, J., Takorabet, N., \&Meibody-Tabar, F. : Optimal design of permanent magnetmotors to improvefield-weakening performances in variable speed drives. IndustrialElectronics, IEEE Transactions on, vol 59 no 6, p. 2484-2494, 2012.

[11] Rahman, M. A., Osheiba, A. M., Kurihara, K., Jabbar, M. A., Ping, H. W., Wang, K., \&Zubayer, H. M. : Advances on single-phase line-starthighefficiencyinterior permanent magnetmotors. IndustrialElectronics, IEEE Transactions on, vol 59 no 3, p. 1333-1345, 2012.

[12] C.C Hwang, J.J. Chang : Design and analysis of a high power density and highefficiency permanent magnet DC motor, Journal of Magnetism and Magnetic Materials, Volume 209, Number 1, February 2000, pp. 234-236(3)-Publisher: Elsevier. 